$\underline{\text { Research Article }}$

\title{
Pilot peer health education for noncommunicable disease prevention in Bangladesh, Ethiopia, and Palau
}

\author{
Lemlem W Gebremariam1, Yoshihisa Hirakawa1, Shahrin E Rayna², Fahmida A Khan², Chifa Chiang ', Yupeng He1, \\ Everlynn J Temengil ${ }^{3}$, Sherilynn Madraisau ${ }^{3}$, Md Khalequzzaman², Sohel R Choudhury4, Hiroshi Yatsuya', \\ Atsuko Aoyama \\ 1 Department of Public Health and Health Systems, Nagoya University School of Medicine, Nagoya, Japan, ${ }^{2}$ Department of Public Health and \\ Informatics, Bangabandhu Sheikh Mujib Medical University, Dhaka, Bangladesh, ${ }^{3}$ Bureau of Public Health Services, Ministry of Health, Koror, Palau, 4 \\ Department of Epidemiology and Research, National Heart Foundation Hospital and Research Institute, Dhaka, Bangladesh \\ Keywords: global health
}

https://doi.org/10.29392/joghr.2.e2018039

\section{Journal of Global Health Reports}

Vol. 2, 2018

\begin{abstract}
Background
Noncommunicable diseases (NCDs) are growing health threats in developing countries. We previously conducted epidemiological and qualitative ethnographic studies on NCD risk factors in Bangladesh, Ethiopia, and Palau, and found that NCD risk factors were significantly prevalent. Although people had some knowledge of NCDs, they had no clue to change their daily risky behaviour, revealing urgent needs for developing appropriate health education programs. Peer health education is a strategy widely applied in developing countries for infectious disease control and maternal and child health, and known to be effective to change behaviour. This article aims to describe the experience of developing peer health education modules and evaluating the trials.
\end{abstract}

\section{Methods}

We conducted pilot peer health education in three different settings: women in an urban slum community in Bangladesh; workers in a regional city in Ethiopia; and young adults in Palau. We modified commonly used education tools according to local socio-cultural context. Then we conducted three-day peer educator training workshops and evaluated the workshops.

\section{Results}

i) Bangladesh. We developed education tools including role plays and gamification, modifying a popular local board game. This motivated the peer educators and nurtured ownership of the module. ii) Ethiopia. We chose topics about dietary habit. We developed an education module including role plays and demonstration of sugar amount in popular beverages. Participants were impressed with such visualized education tools. iii) Palau. As they had some knowledge of NCD risks, we focused on changing attitude. We chose topics about diet, such as reading nutrition labels of canned processed meat.

\section{Conclusion}

We found that peer education is a useful option for NCD prevention in resource-limited settings in developing countries. It is important to take into account of the local priority issues, the level of knowledge of the audience, and the socio-cultural context in each setting. It is also very important to identify who are the peers of the target group. Using locally available and culturally acceptable resources and local language enhances participation and ownership of the people. Peer education for NCD prevention should be integrated into existing primary health care programs.

Noncommunicable diseases (NCDs), including cardiovascular diseases and diabetes, have become an important global public health agenda, ${ }^{1}$ thus reducing the burden of NCDs is cited as one of the targets of the Sustainable Development Goals. ${ }^{2}$ NCDs are growing health threats in low and middle income countries, ${ }^{3}$ where urbanization and lifestyle changes are advancing rapidly, particularly among the people of the low socio-economic status. ${ }^{4,5}$ The World Health Organization (WHO) assists to conduct population-based NCD risk factor surveys, ${ }^{6}$ however, NCDs have not been fully investigated yet in developing countries. Evidencebased practical actions for NCD prevention draw little at- 
tention of people and governments of developing countries, whereas costly NCD treatments seriously concern them. ${ }^{7,8}$

We had conducted a comprehensive study on NCD risk factors, comprised of epidemiological surveys adapting the WHO standard procedure and qualitative ethnographic studies, targeting urban slum dwellers in Bangladesh, 9,10 public employees in a regional city in Ethiopia, ${ }^{11,12}$ and young adults in Palau. ${ }^{13}$ We found that NCD risk factors were significantly prevalent in these population, but they had no clue to change their daily risky behaviour despite their certain amount of knowledge about NCD risks.

By adapting the concept and strategy of primary health care, developing countries often have lots of experience of health education and community participation, focusing on infectious disease control and maternal and child health. Peer education is one of the common approaches of primary health care interventions, such as preventing HIV/AIDS and improving child nutrition. ${ }^{14-16}$ Education by peers is effective to change attitude and behaviour which root deeply in the daily lives and social norms, as peers can be role models who provide feeling of self-efficacy. ${ }^{17}$ Through teaching others, peer educators themselves retain the learned knowledge and improve behaviour much more than those who are taught. Such experience of peer education would be useful to promote NCD prevention activities in the resource-limited settings. ${ }^{18}$

This article aims to describe the experience of developing peer health education modules and evaluating the trials of peer health education in the three different settings. Then, the article discusses the feasibility of peer health education for NCD prevention in the resource-limited settings in developing countries.

\section{METHODS}

\section{STUDY SITE AND TARGET POPULATION}

We targeted three groups of population in different settings. Peer educators were voluntarily recruited among the people belonging to each target group.

i. Bangladesh: Adult women in an urban slum community in Dhaka. The population profile of the community was described elsewhere. ${ }^{19}$ We intended to pilot communitybased approach. We targeted only women, as women and men usually do not spend leisure time together due to local social norms. ${ }^{20}$ In addition, we found that the burden of NCDs were higher in women than in men in the community. ${ }^{9}$

ii. Ethiopia: Public employees in Mekelle, the capital city of Tigray Province in the northern hilly area. We intended to pilot workplace-based approach. Most of the formal sector workers in Mekelle were public employees.

iii. Palau: Young adults including college students in Koror, the most populous area. Our previous epidemiological study revealed that NCD risks were increasing even among young adults. 13

\section{HEALTH EDUCATION TOOLS}

Based on the findings of our previous epidemiological and qualitative ethnographic studies, we chose a few main topics which were important for the target group of people and easy to understand in a limited time. Then, we developed a prototype of health education module to improve knowledge, attitude and skills, choosing commonly used components. ${ }^{21,22}$ The prototype comprised of: lectures on basic NCD knowledge and facilitation skills; question and answer (Q \& A) about some NCD topics; demonstration of nutritional values of popular foods and beverages; gamification; and role plays. Lectures and $\mathrm{Q} \& \mathrm{~A}$ are focusing on knowledge gain, whereas role plays target to improve attitude and skills. Gamification was included to draw attention and interest of the audience.

We adjusted the prototype to the local socio-cultural context through several trials. We first developed health education tools in English. Then we translated the tools for Bangladesh and Ethiopia into the local language, Bengali and Tigrinya, respectively. We used English tools in Palau, as the young adults had been completed at least 12-year formal education in English.

\section{PEER HEALTH EDUCATION WORKSHOPS}

The peer educator training workshops were conducted several times at each setting between November 2015 and January 2018. We organized peer educator training workshops as follows:

1. Day 1: Peer educator training comprised of lectures by the researchers, $\mathrm{Q} \&$ A preparation, demonstration or gamification according to socio-cultural context, and preparation of role play scenarios.

2. Day 2: Health education simulation among the peer educators by conducting health education sessions each other.

3. Day 3: Health education sessions by the trained peer educators to their peers, i.e., some people of the target group of population.

\section{EVALUATION TOOLS}

Expert evaluators, peer educators themselves, and participants of the health education sessions assessed facilitation skills and workshop management according to a standard evaluation format (Appendix S1 in the Online Supplementary Document) ${ }^{23}$ and wrote additional comments, after the Day 2 simulation and the Day 3 health education. As shown in the Online Supplementary Document, five areas of facilitation skills were scored by three to six items (one score each). We also evaluated the changes of knowledge and attitude towards NCDs among peer educators and participants by pre and post workshop tests. In Ethiopia, we conducted focus group interviews of the peer educators for evaluating the overall workshops. In Palau, we assessed changes of attitude by having the peer educator trainees reorder a list of 10 NCD-related/unrelated issues according to the perceived relatedness to NCDs.

\section{ETHICAL CONSIDERATIONS}

This study was reviewed and approved by the Bioethics Review Committee of Nagoya University School of Medicine, Japan (approval no. 2015-0034). Institutional Review Boards of Bangabandhu Sheikh Mujib Medical University 


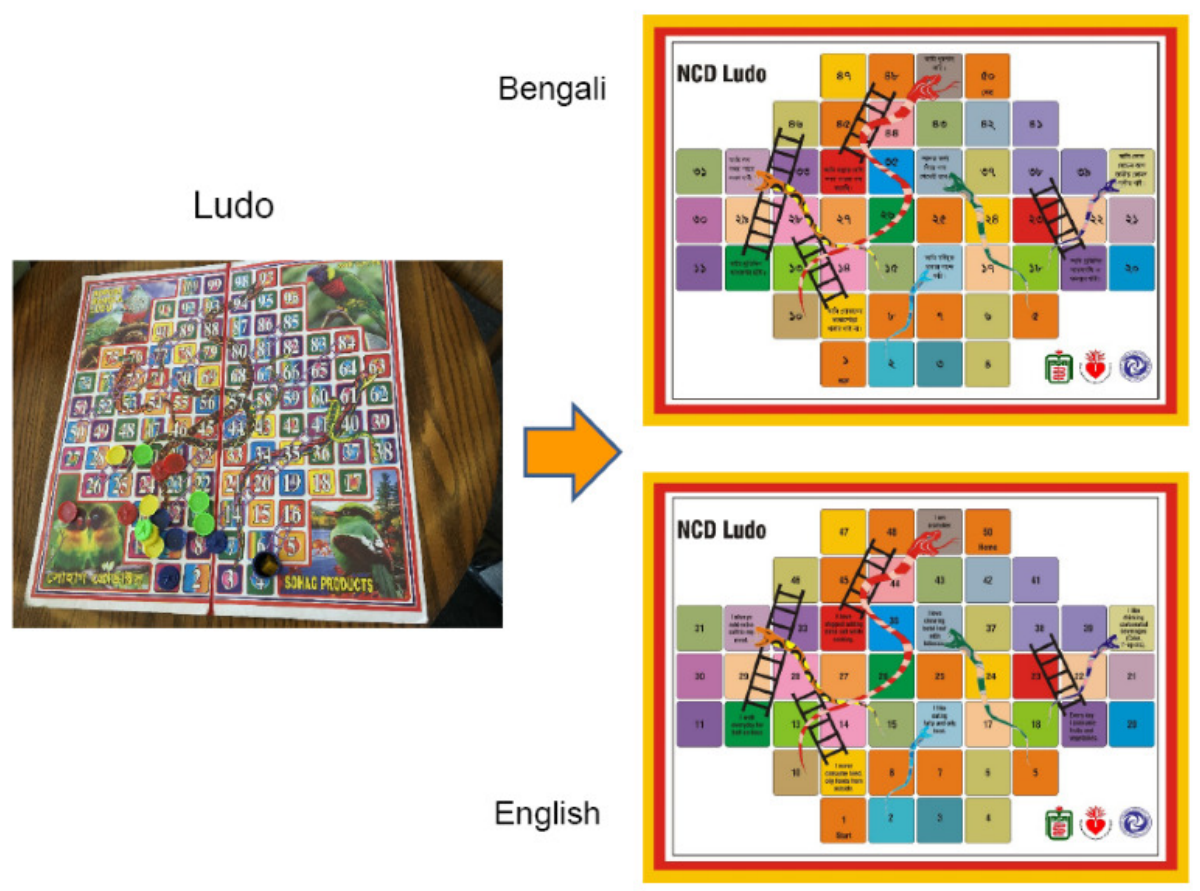

Figure 1. Health education tool based on a local board game in Bangladesh

A popular local board game, called Ludo, was modified to an education tool for learning healthy and unhealthy behaviours. Local women commonly play such board games.

and National Heart Foundation Hospital and Research Institute, Bangladesh, Tigray Health Research Institute of Tigray Regional Health Bureau, Ethiopia, and Ministry of Health, Republic of Palau approved the study as well.

\section{RESULTS}

\section{BANGLADESH PILOT STUDY}

In Bangladesh, we recruited 13 young community women with at least secondary level education and conducted a one-day workshop in November 2016. We tried several health topics and educational tools, including a board game, demonstration of sugar and salt amount, etc., and found that a popular local board game could be modified as an educational tool (Figure 1). We developed a health education module composed of a lecture, Q \& A about risky behaviour, NCD board game, and role plays.

Then, we conducted a three-day workshop in November 2017. We trained 10 women (eight women who had participated in 2016 and two women who newly participated) as peer educators. We split them into two groups and the two group peer educators practiced health education sessions each other. Each group conducted the health education sessions targeting each eight community lay women. Local language, Bengali, was used in the all components of the health education module.

\section{ETHIOPIA PILOT STUDY}

In Ethiopia, we conducted a three-day workshop in October and November 2017, targeting public employees in Mekelle. We chose topics about dietary habit and developed a health education module including a lecture, demonstration of sugar amount in popular beverages, $\mathrm{Q} \& \mathrm{~A}$ about risky behaviour, and role plays. Gamification was excluded, because board games were not popular in Ethiopia. Pre and post tests for assessing knowledge were modified for assessing attitude, as public employees were relatively educated and already had some knowledge.

We recruited peer educator trainees and workshop participants from various offices in the city. Eight public employees volunteered to participate in the two-day peer health educator training workshop. One week later, each peer educator conducted a health education session to the fellow public employees. Local language, Tigrinya, was used in the all components of the health education module.

\section{PALAU PILOT STUDY}

In Palau, we conducted three series of workshops at the Palau Community College (PCC), the only college in the country, in November 2015, January 2017, and January $2018 .^{24}$ The first year, we piloted several health topics, and education and evaluation tools targeting PCC general course students. We found that they already had some knowledge, but did not recognize the need of behavioural change. ${ }^{25}$ The second year, we tried to train PCC public health students as possible peer educators. We found that Q \& A regarding nutrition labels of popular food such as canned processed meat was highly appreciated, but gamification was not so effective as they do not play such board games in Palau.

Then we developed a health education module, composed of a lecture, Q\&A regarding nutrition labels, and role plays. The third year, we piloted each two-day peer health educator training workshops, targeting 24 PCC general and health-related course students and 26 health as- 
sistant trainees, who were at the high school diploma level education. PCC students and health assistant trainees were split into each four groups. We conducted the Day 1 peer educator training and the Day 2 simulation, but did not conduct the Day 3 health education due to time limitation of the peer educator trainees.

\section{EVALUATION OF THE PEER EDUCATOR TRAINING AND HEALTH EDUCATION WORKSHOPS}

Table 1 shows the changes in the evaluation scores of facilitation skills from those after the Day 2 simulation to those after the Day 3 health education in Bangladesh and Ethiopia. Each peer educator evaluated herself and expert evaluators evaluated groups of peer educators in Bangladesh, while both peer educators and expert evaluated each peer educator in Ethiopia. Both expert evaluation and self-evaluation mostly found improvement in facilitation skills, although there were several discrepancies between the expert and self-evaluation. We did not find changes in the evaluation scores in Palau (data not shown).

We conducted pre- and post-tests of NCD knowledge in Bangladesh and those of attitude towards risky behaviour in Ethiopia. However, we could not identify significant changes both in peer educators and workshop participants (data not shown). As shown in Table 2, attitude of the health assistant trainees was improved but that of PCC students did not show much changes in Palau.

Table 3 shows some of the evaluation comments of peer educators, expert evaluators, and participants. In Bangladesh, peer educators felt empowered and were highly motivated with strong feeling of ownership of the health education module and the education tools. The workshop participants also enjoyed the health education tool based on the local popular game and well accepted the health education sessions. Peer educators wished to spread the knowledge in the community, and requested follow-up activities. Expert evaluators from the Ministry of Health mentioned possible integration of such health education into their community health programs.

In Ethiopia, the peer educators and the participants appreciated the health education sessions and suggested to integrate them into the existing HIV/AIDS prevention programs. Peer educators believed that introducing NCD prevention program into their workplaces could save the lives of many workers. They felt that they had learned a lot about NCD prevention and improved their facilitation skills through teaching their peers. While they were interested in the entire contents of the workshop, demonstration of sugar amount in commonly used beverages was most impressive for them. As they were not able to learn everything about NCDs due to time limitation, they would like to have follow-up trainings. They also recommended to issue a peer educator certificate, which would motivate them and make it easy to be accepted by their peers.

In Palau, performance of the health assistant trainees was more effective than that of PCC students, despite their lower education level. This may be due to that health assistant trainees had experience of group work, whereas PCC students had little experience to present anything in front of the audience. Using popular food items as educational tools was well accepted, but misinterpretation of nutrition labels was often found. The PCC students evaluated themselves to have good facilitation skills, whereas other group students and experts evaluated them to have only limited skills. Facilitation skills of health assistant trainees were evaluated to be mostly good by themselves, other group members, and experts. They thought that they understood which lifestyle could affect their health and how they could prevent NCDs through the workshop.

\section{DISCUSSION}

Through the present pilot studies in the three different settings, we found that the peer health education would be a feasible approach for preventing NCDs in the resourcelimited settings in developing countries. Health education modules should take into account of local priority issues, the level of knowledge of the audience, and socio-cultural context. Appreciating local culture and language, we could nurture the ownership of the health education modules through the participatory approach.

Unlike infectious diseases, it is often difficult to realize causes and consequences of NCDs, as most NCDs proceed taking long time without any obvious symptoms. For example, in Bangladesh, local people serve extra salt with meals to their guests as a sign of courtesy, ${ }^{10}$ however, they do not imagine that the over-intake of salt may cause hypertension, and that asymptomatic hypertension may result in stroke, even though they have seen stroke patients in their neighbourhood. Therefore, it is important to connect their general knowledge of NCDs with their specific risky behaviour.

We chose simple messages to warn a risky behaviour such as over-intake of sugar as the first step, ${ }^{26,27}$ because the concept of total dietary energy intake would be difficult to comprehend for most people, who frequently misreport their energy intake. ${ }^{28,29}$ Once the level of knowledge is improved, the message should be elaborated. Careful followup and regular supervision will be required to check the appropriateness of the messages and to maintain the skills and motivation of the peer educators.

The structure of the community and cultural context need to be explored to find out who are the "peers". ${ }^{30} \mathrm{We}$ could not include both genders at the same time for the community-based approach piloted in Bangladesh. Living in the same slum community, men and women mostly shared similar socio-economic status. However, men and women spend leisure time separately, due to the local social norm. ${ }^{20}$ Therefore, men and women should be regarded as belonging to the different "peer" groups. Similarly, we may need to consider occupational levels for the workplacebased approach piloted in Ethiopia, in case they belong to the same workplace. ${ }^{31}$ We recruited participants from different offices for this pilot study, thus we did not need to consider the occupational levels. However, it might be difficult for a lower-level employee to teach higher-level ones in the real workplace environment.

We included reading nutrition labels of popular food items in Palau, as they had general knowledge of NCDs but did not relate it to their daily diets. In Palau, most married women take full time jobs, and spend little time for cook- 
Table 1. Changes in the evaluation scores of facilitation skills in Bangladesh and Ethiopia*

\begin{tabular}{|c|c|c|c|c|c|c|}
\hline $\begin{array}{l}\text { Peer } \\
\text { Educator }\end{array}$ & Evaluator & $\begin{array}{c}\text { Engaging } \\
\text { skills }\end{array}$ & $\begin{array}{l}\text { Informing } \\
\text { skills }\end{array}$ & $\begin{array}{l}\text { Involving } \\
\text { skills }\end{array}$ & $\begin{array}{l}\text { Applying } \\
\text { skills }\end{array}$ & $\begin{array}{c}\text { Conducting an } \\
\text { activity }\end{array}$ \\
\hline \multicolumn{7}{|c|}{ Bangladesh } \\
\hline Group A & Expert & +1.4 & +0.6 & -0.2 & +0.2 & +0.2 \\
\hline PE 1 & & +1 & - & +1 & +1 & - \\
\hline PE 2 & & - & - & +2 & +1 & - \\
\hline PE 3 & Self & +1 & - & - & +2 & -1 \\
\hline PE 4 & & +1 & - & - & +1 & - \\
\hline PE 5 & & +1 & - & - & +2 & -1 \\
\hline Group B & Expert & +3.4 & +1.4 & +0.8 & +0.2 & +0.6 \\
\hline PE 6 & & - & - & - & +1 & +2 \\
\hline PE 7 & & - & - & +1 & +1 & +1 \\
\hline PE 8 & Self & - & +1 & - & - & +1 \\
\hline PE 9 & & - & - & - & +1 & +1 \\
\hline PE 10 & & - & - & - & - & - \\
\hline \multicolumn{7}{|l|}{ Ethiopia } \\
\hline \multirow[t]{2}{*}{ PE 1} & Expert & - & +2 & - & - & - \\
\hline & Self & - & - & - & -1 & +1 \\
\hline \multirow[t]{2}{*}{ PE 2} & Expert & - & -1 & - & +1 & +2 \\
\hline & Self & +3 & - & +2 & -1 & +2 \\
\hline \multirow[t]{2}{*}{ PE 3} & Expert & - & - & - & +3 & - \\
\hline & Self & +1 & - & +1 & - & - \\
\hline \multirow[t]{2}{*}{ PE 4} & Expert & +1 & +3 & +3 & - & +2 \\
\hline & Self & - & - & +3 & +1 & +1 \\
\hline \multirow[t]{2}{*}{ PE 5} & Expert & -2 & - & - & -1 & -1 \\
\hline & Self & +2 & - & -1 & +1 & +3 \\
\hline \multirow[t]{2}{*}{ PE 6} & Expert & +1 & - & - & - & +1 \\
\hline & Self & +1 & - & +2 & +1 & +1 \\
\hline \multirow[t]{2}{*}{ PE 7} & Expert & +2 & - & +3 & +1 & +1 \\
\hline & Self & +1 & - & +2 & +2 & +1 \\
\hline \multirow[t]{2}{*}{ PE 8} & Expert & +1 & +2 & - & +2 & - \\
\hline & Self & - & - & +1 & -1 & +3 \\
\hline
\end{tabular}

PE - peer educator

*Changes in the evaluation scores of facilitation skills from the scores after the Day 2 simulation to the scores after the Day 3 health education. $+0.2-3.4$ : improving; $-0.2-2$ : worsening; -: no change.

ing family meals, unlike the older generation. Thus, readymade food such as canned processed meat is very popular and easily available, making it crucial for them to understand the nutritional value of such ready-made food. Previous studies also reported association of nutrition label understanding with better dietary behaviour. ${ }^{32,33}$

However, peer educators did not fully understand that the labels showed values of one serving, but not the total amount in the whole can or bag. This finding is similar to the findings of a previous study in the United States reporting that many consumers had difficulty interpreting nutrition labels. ${ }^{32}$ Such difficulty in Palau might be partly caused by the limited mathematical skills and difficulty in understanding in English. Although English is widely used at all levels of formal education in Palau, even young adults use Palauan for daily conversation. Local language, Palauan, should be used for health education, as well as nutrition la- bels, even though English is used widely. It also needs to regulate nutrition labels in Palau to make them easy-toread for everyone.

We found improvement of facilitation skills of the peer educator trainees and favourable evaluation comments by the experts and the peer educator trainees themselves. As we intended, the first evaluation after the Day 2 simulation seemed to have worked as post simulation debriefing which gave reflection and feedback of their performance. Similar to the findings of previous studies on health professional education, 34,35 we found that such debriefing brought the improvement in the second evaluation after the Day 3 health education.

However, we could not identify much changes of attitude. This might be partly due to the short period of time between pre and post tests. The insignificant attitude change might be the result of the insufficient post simula- 
Table 2. Changes of attitude towards NCD-related/unrelated issues among the peer educator trainees in Palau*

\begin{tabular}{lcccc} 
& \multicolumn{2}{c}{ Health assistant trainees } & \multicolumn{2}{c}{ PCC students } \\
& Pre test & Post test & Pre test & Post test \\
\hline Overweight & 8 & 9 & 8 & 8 \\
Physical inactivity & 5 & 6 & 8 & 8 \\
Unbalanced diet & 7 & 7 & 7 & 7 \\
Fruit \& vegetable & 9 & 5 & 9 & 9 \\
Salt & 6 & 9 & 7 & 6 \\
Alcohol & 4 & 9 & 6 & 7 \\
Coke & 6 & 8 & 5 & 4 \\
Tobacco & 2 & 9 & 5 & 6 \\
Virus & 8 & 1 & 5 & 5 \\
Radiation & 2 & 2 & 5 & 4 \\
\hline
\end{tabular}

PCC - Palau Community College, NCD - noncommunicable disease

*Scores of the perceived NCD-relatedness. 9: most related to NCDs; 1: least related to NCDs.

tion debriefing. Due to time limitation of the participants, we could not conduct a full length of debriefing, including video-monitoring and group discussions, at each simulation workshop, although our previous study indicated the effectiveness of such full debriefing. ${ }^{36}$ Another reason could be the evaluation indicators insufficient to measure changes of attitude. As we found that most peer educators and participants had some general knowledge of NCDs, we modified the original knowledge checklists to attitude checklists, which might not be clear enough to measure changes of attitude. In addition, peer educators might not have fully understood about their roles, thus they were more interested in gaining own knowledge than delivering messages to others. It is important to plan the workshop according to the readiness of participants.

Peer education approach has been widely applied to public health programs, such as HIV prevention and adolescent reproductive health, in neighbouring countries in Asia ${ }^{37-39}$ and Africa. ${ }^{40-42}$ Similar to our findings, previous studies in such countries reported: importance of identifying proper peers; increased self-efficacy of peer educators; and effectiveness for changing behaviour.

Strengths of this study are: the pilot programs were developed based on the objective data; the pilots covered three different settings in low and middle income countries; and local socio-cultural contexts were integrated into the program. Limitations of this study include followings. We conducted only small scale pilots, thus the outcome of the up-scaled programs is uncertain. We could not use an exactly same evaluation format in the three different settings, due to the different environment. The evaluation was subjectively scored and the evaluators might be biased for favourable results, but we triangulated the evaluation scores to increase objectivity. We could not measure longterm behavioural changes because of time limitation. However, the objective of this study was to assess feasibility of such approach, therefore, long term impacts should be measured in the future studies.

\section{CONCLUSIONS}

Peer health education is a useful option for preventing NCDs in resource-limited settings. It is important to take into account of the socio-cultural context in each setting. Local participation and ownership is enhanced by using locally available and culturally acceptable resources, and local language. Proper follow-up activities are required to sustain and upgrade the activities. Peer health education for NCD prevention should be integrated into the existing primary health care programs.

\section{ACKNOWLEDGEMENTS}

The authors wish to thank the participants of this pilot studies; Department of Epidemiology and Research, National Heart Foundation Hospital and Research Institute (Bangladesh); Department of Public Health and Informatics, Bangabandhu Sheikh Mujib Medical University (Bangladesh); Bureau of Health Education and Promotion, Directorate General of Health Services, Ministry of Health and Family Welfare (Bangladesh); Tigray Regional Health Bureau (Ethiopia); Ministry of Health (Palau); Palau Community College (Palau); and Palau Resource Institute (Palau).

\section{FUNDING}

This work was supported by Sciences Research Grant for Research on Global Health Issues from Japan Agency for Medical Research and Development (15-17jk0110008h0101-03 to AA). The funder of the study had no role in study design, data collection, data analysis, data interpretation, or writing of the article.

\section{COMPETING INTERESTS}

The authors completed the Unified Competing Interest form at http://www.icmje.org/coi disclosure.pdf (available 
Table 3. Comments by the expert evaluators, peer educators, and participants

\begin{tabular}{|c|c|}
\hline Country & Comments \\
\hline \multirow{12}{*}{ Bangladesh } & Positive aspects \\
\hline & Peer educators prepared and played excellent role plays. \\
\hline & Peer educators had innovative ideas to use local drinks and snacks. \\
\hline & Participants really enjoyed playing NCD Ludo. \\
\hline & Peer educators requested follow-up activities. \\
\hline & The $\mathrm{MOH}$ evaluators implied possible integration to their programs. \\
\hline & Challenges \\
\hline & Time management of the sessions was not well enough. \\
\hline & It had better to assign a group leader of peer educators. \\
\hline & Some peer educators presented unnecessary global issues. \\
\hline & Peer educators should smile more and make eye contact with the participants. \\
\hline & Not all participants were included in the discussion. \\
\hline \multirow{15}{*}{ Ethiopia } & Positive aspects \\
\hline & Most peer educators improved their facilitation skills after the sessions. \\
\hline & They had appropriate voice tone. \\
\hline & They improved their confidence and managed to avoid confusion. \\
\hline & They could answer questions correctly. \\
\hline & They could summarize the sessions and deliver key messages. \\
\hline & Most of the sessions were participatory. \\
\hline & Peer educators believed such programs could save the lives of workers. \\
\hline & They felt their knowledge and skills were improved by teaching others. \\
\hline & Demonstration of sugar amount in popular beverages was impressive. \\
\hline & They would like to have follow-up trainings. \\
\hline & Peer educator certificate should be issued. \\
\hline & Challenges \\
\hline & Most peer educators were not able to manage time properly. \\
\hline & Some peer educators were nervous and unable to organize the sessions well \\
\hline \multirow{15}{*}{ Palau } & Positive aspects \\
\hline & Most groups, especially health assistant trainees' groups, facilitated well. \\
\hline & It was good to use commonly consumed foods and beverages. \\
\hline & It was good to show the amount of sugar in soda by the numbers of teaspoons. \\
\hline & They were innovative to use locally available materials for role plays. \\
\hline & They were able to prepare relevant $Q \& A$ and give factual explanations. \\
\hline & Peer educators could present with appropriate voice tone. \\
\hline & They thought they understood what lifestyle affected their health. \\
\hline & Facilitation skills of health assistant trainees were mostly good. \\
\hline & Challenges \\
\hline & Written texts of $Q \& A$ were too small to read. \\
\hline & They were sometimes unable to give proper explanations of $Q \& A$. \\
\hline & Some $Q \& A$ did not take into account serving volume of food and beverage. \\
\hline & They often made mistakes in simple calculations. \\
\hline & $\begin{array}{l}\text { Facilitation skills of college students were limited, although they evaluated } \\
\text { themselves to be good. }\end{array}$ \\
\hline
\end{tabular}

Q \& A - questions and answers

upon request from the corresponding author), and declare no conflicts of interest.

\section{CORRESPONDENCE TO:}

Atsuko Aoyama, MD, PhD

Department of Public Health and Health Systems 
Nagoya University School of Medicine

65 Tsurumai-cho, Showa-ku
Nagoya 466-8550 Japan

atsukoa@med.nagoya-u.ac.jp

This is an open-access article distributed under the terms of the Creative Commons Attribution 4.0 International License (CCBY-4.0). View this license's legal deed at http://creativecommons.org/licenses/by/4.0 and legal code at http://creativecommons.org/licenses/by/4.0/legalcode for more information. 


\section{REFERENCES}

1. World Health Organization. Global Status Report on Noncommunicable Diseases 2014. WHO; 2014.

2. Sustainable development goal 3: Ensure healthy lives and promote well-being for all at all ages. Accessed June 22, 2018. https://sustainabledevelopme nt.un.org/sdg3

3. WHO. Global Health Observatory data repository, Noncommunicable diseases, Mortality. Accessed June 22, 2018. http://apps.who.int/gho/data/node.main.A8 59?lang=en

4. Allen L, Williams J, Townsend N, et al. Socioeconomic status and non-communicable disease behavioural risk factors in low-income and lowermiddle-income countries: a systematic review. Lancet Glob Health. 2017;5(3):e277-e289. doi:10.1016/s221 4-109x(17)30058-x

5. Wu H, Meng X, Wild SH, Gasevic D, Jackson CA. Socioeconomic status and prevalence of type 2 diabetes in mainland China, Hong Kong and Taiwan: a systematic review. J Glob Health. 2017;7:011103. do i: $10.7189 /$ jogh. 07.011103

6. WHO. Noncommunicable diseases and their risk factors, STEPwise approach to surveillance (STEPS). Accessed. Published June 22, 2018. Accessed June 22, 2018. http://www.who.int/ncds/surveillance/steps/en/

7. Barcelo A, Arredondo A, Gordillo-Tobar A, Segovia J, Qiang A. The cost of diabetes in Latin America and the Caribbean in 2015: Evidence for decision and policy makers. J Glob Health. 2017;7(2):020410. doi:1 $\underline{0.7189 / j \operatorname{jogh} .07 .020410}$

8. Dugee O, Palam E, Dorjsuren B, Mahal A. Who is bearing the financial burden of non-communicable diseases in Mongolia? J Glob Health. 2018;8:010415. d oi:10.7189/jogh.08.010415

9. Khalequzzaman M, Chiang C, Choudhury SR, et al. Prevalence of non-communicable disease risk factors among poor shantytown residents in Dhaka, Bangladesh: a community-based cross-sectional survey. BMJ Open. 2017;7(11):e014710. doi:10.1136/b miopen-2016-014710

10. Al-Shoaibi AAA, Matsuyama A, Khalequzzaman M, Haseen F, Choudhury SR, Hoque BA. Perception and behavior related to noncommunicable diseases among slum dwellers in rapidly urbanized transitional city, Dhaka, Bangladesh: a qualitative study. Nagoya J Med Sci. 2018;80.
11. Gebremariam LW, Chiang C, Yatsuya H, et al. Non-communicable disease risk factor profile among public employees in a regional city in northern Ethiopia. Sci Rep. 2018;8:9298. doi:10.1038/s41598-0 18-27519-6

12. Gebremariam LW, Aoyama A, Kahsay BA, Hirakawa Y, Chiang C, Yatsuya H. Perception and practice of 'healthy' diet in relation to noncommunicable diseases among the urban and rural people in northern Ethiopia: a communitybased qualitative study. Nagoya J Med Sci. 2018;80.

13. Chiang C, Singeo, Jr ST, Yatsuya H, et al. Profile of non-communicable disease risk factors among young people in Palau. J Epidemiol. 2015;25(5):392-397. oㅡ i:10.2188/iea.je20140156

14. Medley A, Kennedy C, O’Reilly K, Sweat M. Effectiveness of peer education interventions for HIV prevention in developing countries: a systematic review and meta-analysis. AIDS Educ Prev. 2009;21(3):181-206. doi:10.1521/aeap.2009.21.3.181

15. Adeomi AA, Adeoye OA, Asekun-Olarinmoye EO, Abodunrin OL, Olugbenga-Bello AI, Sabageh AO. Evaluation of the effectiveness of peer education in improving HIV knowledge, attitude, and sexual behaviours among in-school adolescents in Osun state, Nigeria. AIDS Res Treat. 2014;2014:131756. do i:10.1155/2014/131756

16. Duncanson K, Burrows T, Collins C. Peer education is a feasible method of disseminating information related to child nutrition and feeding between new mothers. BMC Public Health. 2014;14:1262. doi:10.1186/1471-2458-14-1262

17. Foley BC, Shrewsbury VA, Hardy LL, Flood VM, Byth K, Shah S. Evaluation of a peer education program on student leaders' energy balance-related behaviors. BMC Public Health. 2017;17:695. doi:10.11 86/s12889-017-4707-8

18. Rabkin M, El-Sadr WM. Why reinvent the wheel? Leveraging the lessons of HIV scale-up to confront non-communicable diseases. Glob Public Health. 2011;6(3):247-256. doi:10.1080/17441692.2011.55206 $\underline{8}$

19. Khalequzzaman M, Chiang C, Hoque BA, et al. Population profile and residential environment of an urban poor community in Dhaka, Bangladesh. Environ Health Prev Med. 2017;22:1. doi:10.1186/s12199-01 7-0610-2 
20. Offenhauer P. Women in Islamic Societies: A Selected Review of Social Scientific Literature. Federal Research Division, Library of Congress; 2005.

21. Lawson K. The Trainer's Handbook. 2nd ed. Pfeiffer; 2006.

22. WHO Regional Office for the Eastern Mediterranean. Health Education: Theoretical Concepts, Effective Strategies and Core Competencies: A Foundation Document to Guide Capacity Development of Health Educators. WHO Regional Office for the Eastern Mediterranean; 2012.

23. Brooks-Harris JE, Stock-Ward SR. Workshops: Designing and Facilitating Experiential Learning. Sage Publications; 1999.

24. Aoyama A, Chiang C, Mita T, Kawazoe N. Recommendations for evidence-based NCD prevention strategies in Palau - Non-communicable diseases (NCD) as a post MDG global health issue. In: Proceeding of the 16th Spring Conference of Japan Society for International Development. ; 2015:200-203.

25. Hirakawa Y, Chiang C, Hasebe Y, Mita T, Aoyama A. A trial for practical education on noncommunicable diseases for Palauan young people. In: Proceeding of the 17th Spring Conference of Japan Society for International Development. ; 2016:182-185.

26. Pechmann C, Zhao G, Goldberg ME, Reibling ET. What to convey in antismoking advertisements for adolescents: the use of protection motivation theory to identify effective message themes. J Mark. 2003;67(2):1-18. doi:10.1509/jmkg.67.2.1.18607

27. Murdock MR, Rajagopal P. The sting of social: how emphasizing social consequences in warning messages influences perceptions of risk. J Mark. 2017;81(2):83-98. doi:10.1509/jm.15.0402

28. Leslie WS, Eunson J, Murray L, Lean MEJ, Hankey CR. What, not just salad and veg? Consumer testing of the eatwell week. Public Health Nutr. 2013;17(7):1640-1646. doi:10.1017/s13689800130016 $\underline{63}$

29. Vainik U, Konstabel K, Lätt E, Mäestu J, Purge P, Jürimäe J. Diet misreporting can be corrected: confirmation of the association between energy intake and fat-free mass in adolescents. Br J Nutr. 2016;116(8):1425-1436. doi:10.1017/s0007114516003 $\underline{317}$

30. Sussman S, Pokhrel P, Ashmore RD, Brown BB. Adolescent peer group identification and characteristics: a review of the literature. Addict Behav. 2007;32(8):1602-1627. doi:10.1016/j.addbeh.2 $\underline{006.11 .018}$
31. Dickinson D. Workplace HIV/AIDS Peer Educators in South African Companies. Wits Business School; 2006.

32. Persoskie A, Hennessy E, Nelson WL. US consumers' understanding of nutrition labels in 2013: the importance of health literacy. Prev Chronic Dis. 2017;14:e86. doi:10.5888/pcd14.170066

33. Christoph MJ, Larson N, Laska MN, NeumarkSztainer D. Nutrition facts panels: who uses them, what do they use, and how does use relate to dietary intake? J Acad Nutr Diet. 2018;118(2):217-228. doi:1 $\underline{0.1016 / j . j a n d .2017 .10 .014}$

34. Levett-Jones T, Lapkin S. A systematic review of the effectiveness of simulation debriefing in health professional education. Nurse Educ Today. 2014;34(6):e58-e63. doi:10.1016/j.nedt.2013.09.020

35. Oikawa S, Berg B, Turban J, Vincent D, Mandai Y, Birkmire-Peters D. Self-debriefing vs instructor debriefing in a pre-internship simulation curriculum: night on call. Hawaii J Med Public Health. 2016;75:127-132.

36. Hirakawa Y, Chiang C, Hilawe EH, Andoh H, Uemura K, Aoyama A. Formative research for the nationwide promotion of a multidisciplinary community-based educational program on end-of-life care. Nagoya J Med Sci. 2017;79:229-239. doi:10.1016/ j.jand.2017.10.014

37. Hull TH, Hasmi E, Widyantoro N. "Peer” educator initiatives for adolescent reproductive health projects in Indonesia. Reprod Health Matters. 2004;12(23):29-39. doi:10.1016/s0968-8080(04)2312 $\underline{0-2}$

38. Morisky DE, Nguyen C, Ang A, Tiglao TV. HIV/ AIDS prevention among the male population: results of a peer education program for taxicab and tricycle drivers in the Philippines. Health Educ Behav. 2005;32:57-68. doi:10.1177/1090198104266899

39. Van Rompay KKA, Madhivanan P, Rafiq M, Krupp $\mathrm{K}$, Chakrapani V, Selvam D. Empowering the people: development of an HIV peer education model for low literacy rural communities in India. Hum Resour Health. 2008;6:6. doi:10.1186/1478-4491-6-6

40. Laukamm-Josten U, Mwizarubi BK, Outwater A, et al. Preventing HIV infection through peer education and condom promotion among truck drivers and their sexual partners in Tanzania, 1990-1993. AIDS Care. 2000;12:27-40. doi:10.1080/09540120047440 
41. Miller AN, Mutungi M, Facchini E, Barasa B, Ondieki W, Warria C. An outcome assessment of an ABC-based HIV peer education intervention among Kenyan university students. J Health Commun. 2008;13(4):345-356. doi:10.1080/10810730802063470
42. Gebreyohanes G, Khali EAG, Tsige Z, Ali F. The effect of peer education on peer educators' reproductive health knowledge, attitude, health service use and their personal development. Int J Sci Basic Appl Res. 2015;20:294-312. 